\title{
Urban toys komunikasi visual sebagai citra intermix tradisional dan budaya populer
}

\author{
Rani Chandra Oktaviani \\ Sekolah Tinggi Ilmu Komunikasi LSPR
}

\begin{abstract}
ABSTRAK
Urban toys, khususnya di Indonesia semakin berkembang, terpaan urban toys sebagai karya populer dinilai akan mengikis unsur budaya tradisional. Sebelumnya "Toys" hanya diartikan sebagai mainan yang diproduksi untuk mainan anak, namun pada tahun 90an hingga 2000 awal, muncul toys movement, dimana mainan bukan hanya sekedar menyodorkan keunikan bentuk, namun memiliki konsep dan gagasan yang berusaha dikomunikasikan oleh designer/artis kepada khalayak. Artis Indonesia juga mulai menaruh muatan tradisional kedalam karya urban toys mereka. Penelitian ini bertujuan untuk mengetahui fungsi, model komunikasi, aspek dominan dan identifikasi komunikasi visual literasi artis urban toys di Indonesia. Penelitian ini mengangkat teori literasi visual, konsep komunikasi visual, dengan metodologi penelitian menggunakan kualitatif deskriptif. Narasumber penelitian ini adalah beberapa designer toys Indonesia yang telah ditentukan secara spesifik berkaitan dengan fokus penelitian. Penelitian ini menghasilkan beberapa temuan diantaranya urban toys dalam komunikasi visual memiliki fungsi visualisasi karya seni, kritik sosial, aspirasi politik lokal, hingga pesan budaya tradisional. Terdapat dua model komunikasi artis dalam membuat urban toys yaitu melalui proses original dan customize. Aspek komunikasi visual lebih dominan pada mediated message, yakni urban toys sebagai media perantara dalam penyampaian pesan budaya Indonesia. Literasi komunikasi visual artis Indonesia diidentifikasi pada advance level. Jika dikaitkan dengan kompetensi artis, maka fokus berada pada penerapan beberapa aspek yaitu adanya proses konstruksi, kemampuan menggambarkan visualisasi tiga dimensi, produksi original konseptualiasi, dan produksi konsep mix communication. Simpulan penelitian ini menekankan pada implikasi teoretis yang menunjukan bahwa urban toys dengan konsep budaya populer yang dinilai dapat melunturkan budaya tradisional, dapat dikombinasikan dengan konsep dan pesan tradisional.
\end{abstract}

Kata-kata Kunci:Designer toys; komunikasi visual; literasi visual; budaya; intermix

\section{Urban toys visual communication as an intermix image of traditional and popular culture}

\begin{abstract}
Urban toys, especially in Indonesia is growing exponentially, as popular work, it is considered to erode the elements of traditional culture. Previously, "Toys" was only interpreted as children's entertainment, but in the 90s to early 2000, there was a toys' movement, where toys were not merely offering a unique form but also concepts and ideas of a designer/artist. Indonesian artists begin to put traditional content into their work. This study aims to determine the functions, models, dominant aspects, and identification of literacy visual communication of urban toys artists in Indonesia. This study uses the theory of visual literacy and visual communication. The research methodology of the research uses descriptive qualitative. The informants purposively chosen are Indonesian toys'designers. This study shows that urban toys in visual communication have the function of visualizing works of art, social criticism, local political aspirations, and cultural messages. There are two models of urban toys artist's communication: original and custom processes. The visual communication aspect is more dominant in the mediated message, namely urban toys as an intermediary media in conveying the message of Indonesian culture. Indonesian toys'artist literacy on visual communication was identified on the advanced level. The level of artist's competency was associated with several aspects in the construction process, the ability to describe three-dimensional visualization, original production conceptualization, and the production of the mix communication concept. The theoretical implications in this study show that urban toys with the idea of popular culture can deliver a message about traditional Indonesia.
\end{abstract}

Keywords: Designer toys; visual communication; visual literacy; culture; intermix

Korespondensi: Rani Chandra Oktaviani. LSPR. Sudirman Park Campus, Jl. Jend. Sudirman No.Kav. 32, Karet Tengsin, Daerah Khusus Ibukota Jakarta 10250.Email: rani.co@1spr.edu 


\section{PENDAHULUAN}

Perkembangan dunia mainan (Toys) telah menciptakan suatu fenomena tersendiri, dahulu "Toys" diidentikan sebagai mainan anak-anak dan tidak memiliki arti lebih dari sekedar instrumen hiburan semata. Namun di awal tahun 2000an muncul suatu fenomena "Toys Movement" yakni bahwa "Toys" bukan hanya sekedar mainan anak, melainkan menjadi suatu media yang digemari oleh orang dewasa dengan berbagai aplikasi fungsi (Bandung Magazine, 2015). Sejak itu beberapa kalangan menjadikan toys sebagai sarana expresi diri yaitu sarana hiburan, hobi, koleksi, hingga menjadikan toys sebagai media komunikasi dalam menuangkan gagasan baik dalam bentuk karya seni, kritik, ide ataupun penyampaian idelogi tertentu.

Sejak mulainya era tersebut, toys yang memiliki konsep dikenal dengan istilah Urban Vinyl/Designer Toys/Art Toy atau Urban toys. Berkembangnya istilah tersebut memunculkan perbedaan yang mendasar antara mainan anakanak dengan urban toys yang memiliki konsep tersendiri, yang menyasar berbagai kalangan. Beberapa penelitian telah memaparkan bahwa produk mainan ini berusaha memasukan ide dan konsep dan nilai seni menggiring persepsi khalayak. Seperti yang disampaikan pada kutipan hasil penelitian sebelumnya sebagai berikut:

"Designer Toys" which is also named as "Urban toys, Urban Vinyl, Art Toys" which has been developing since the end of 1990's and defined as artistic/design movement today occurs with the perception of aesthetic and production consumption which improved with DIY culture in the sense of approach and idea" (Atilgan, 2014).

Urban toys sendiri didesain sedemikian rupa oleh para pembuat toys yang dikenal juga sebagai perancang ide dan gagasan yakni seorang "Artis". Gagasan karya yang dibuat bisa bersumber dari pengalaman, lingkungan sekitar, pemikiran, hingga murni hasil karya imajinasi artis yang membuat.

Melihat adanya perubahan peran dan fungsi mainan, yang tidak hanya sekedar sarana hiburan, maka akan sangat menarik untuk diteliti bagaimana toys berfungsi sebagai media dalam menyampaikan gagasan/konsep dalam bentuk visual. Konteks penelitian ini melihat urban toys dari sudut pandang ilmu komunikasi, yaitu dari fenomena urban toys yang menjadi sebuah media baru dalam menyampaikan gagasan. Dengan menggunakan cara pandang komunikasi, kajian urban toys ini berusaha menjelaskan bagaimana proses komunikasi visual dari seorang artis urban toys dalam menuangkan ide dan gagasan sebagai bentuk penyampaikan pesan melalui karyanya.

Ruang lingkup penelitian ini mengambil objek penelitian di Indonesia, dimana perkembangan urban toys selain di luar negeri 
juga mulai marak di dalam negeri. Penelitian ini berusaha memaparkan bagaimana artis Indonesia berusaha mengemas pesan ke dalam karya urban toys yang dibuat dengan kekhasan tersendiri.

Tidak hanya tema budaya populer yang menjadi tema karya artis urban toys Indonesia, namun juga yang menarik artis Indonesia menjadikan tema lokal dan konsep tradisional menjadi alternatif gagasan yang dituangkan kedalam karya. Sebenarnya gagasan ini merupakan bagian dari terjemahan ideologi yang berusaha diusung oleh artis lokal Indonesia, mereka berharap dengan menaruh konten tradisional, menjadikan urban toys sebagai media penyampai pesan budaya.

Melihat adanya penggabungan kultur populer dan tradisional inilah yang menjadi kekhasan dari karya artis Indonesia. Berikut adalah contoh karya artis Indonesia yang menggabungkan unsur populer dan tradisional, dimana mereka menggunakan platform urban toys populer seperti bentuk "Dunny" untuk kemudian dijadikan mainan bertema tradisional.

Gambar 1 terdiri dari tiga bentuk urban toys, paling kiri adalah mass produk urban toys dalam bentuk platform/blank, kemudian yang ditengah merupakan contoh karakter urban toys dengan nuansa art populer, sedangkan yang paling kanan adalah karya artis Indonesia yang memadukan platform budaya populer yakni
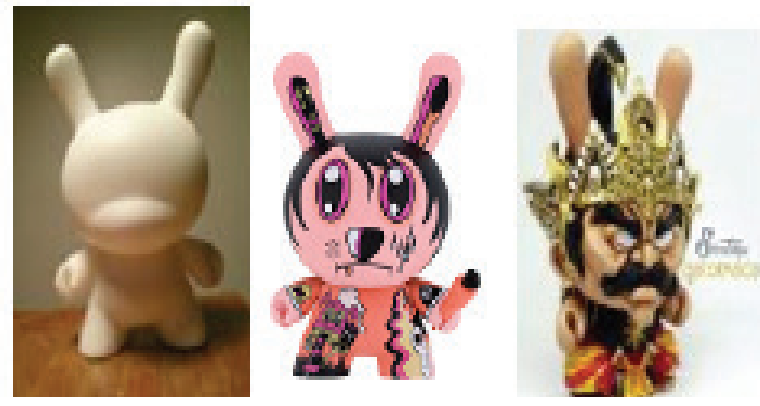

Sumber: Kidrobot.com, (gnberg, 2010), (Tampi)

Gambar 1. Urban toys dengan platform Dunny

Dunny dengan bentuk visual budaya tradisional yaitu Gatot koco.

Urban toys di Indonesia, semakin hari semakin marak dengan bertambahnya pembelian dan produksi dari artis lokal. Antusiasme di Indonesia terlihat dengan meningkatnya pembelian Urban toys dari luar negeri dan juga oleh masyarakat Indonesia. Beberapa yang menggandrungi bukan hanya sekedar membeli, namun juga sebagai koleksi mainan. Peningkatan produksi juga ditandai dengan semakin bermunculannya karya urban toys karya anak bangsa.

Indonesia saat ini dikenal memiliki banyak artis yang berkecimpung di dunia urban toys. Beberapa artis yang ada berasal dari pelaku hobi, desainer grafis, artis graffiti, illustrator dan pelaku seni murni. Setiap tahunnya artis urban toys semakin sering menampilkan dirinya baik secara individu maupun melalui komunitas. Beberapa komunitas artis urban toys Indonesia yang didalamnya beranggotakan artis, baik senior ataupun pemula adalah: 1) IAT 
(Indonesian Art Toys) memiliki kurang lebih 500

Artis. (Yusrini, 2017). 2) Sotoy (Self Original Toys) memiliki 8 artis. 3) Mute Kolektif yang memiliki kurang lebih 3 anggota.

Dengan bermunculannya artis dan komunitas, urban toys di Indonesia semakin berkembang, bahkan dalam pembuatan karyanya tidak hanya sekedar membawa gagasan individu melainkan menciptakan konsep kolektif dari komunitas.

Sejalan dengan bertumbuhnya urban toys di Indonesia, berkembang pula event-event yang spesifik memamerkan karya urban toys, baik karya lokal maupun produksi pabrik luar negeri. Beberapa event besar yang setiap tahun berjalan sebagai sarana publikasi urban toys dapat dilihat pada tabel 1 .

Tabel 1 Event Urban toys Dalam Negeri

\begin{tabular}{|c|c|c|c|}
\hline No & $\mathbf{N} \underset{\text { Event }}{\mathbf{a}} \mathbf{m} a$ & Tempat & Waktu \\
\hline 1 & $\begin{array}{ll}\text { Pop } & \text { Con } \\
\text { Asia } & \end{array}$ & $\mathrm{JCC}$ & $\begin{array}{l}\text { R e gu le r } \\
\text { Tahunan }\end{array}$ \\
\hline 2 & $\begin{array}{l}\text { Indonesia } \\
\text { Comic Con }\end{array}$ & $\mathrm{JCC}$ & $\begin{array}{l}\text { R e g u l e r } \\
\text { Tahunan }\end{array}$ \\
\hline 3 & $\begin{array}{l}\text { Battle of } \\
\text { The Toys }\end{array}$ & $\begin{array}{l}\text { Balai Kartini/ } \\
\text { Ke m a y or an } \\
\text { Convention } \\
\text { Centre }\end{array}$ & $\begin{array}{l}\text { Regule } \mathrm{r} \\
\text { Tahunan }\end{array}$ \\
\hline 4 & $\begin{array}{l}\text { Jakarta Toys } \\
\& \text { Comic }\end{array}$ & Balai Kartini & $\begin{array}{l}\text { R e gu le r } \\
\text { Tahunan }\end{array}$ \\
\hline 5 & $\begin{array}{l}\text { StarWords } \\
\text { Day }\end{array}$ & Kuningan City & Periodik \\
\hline 6 & $\begin{array}{l}\mathrm{R} \text { e } \mathrm{a} \\
\text { American } \\
\text { Heros }\end{array}$ & Kuningan City & Periodik \\
\hline 7 & $\begin{array}{l}\text { Urban toys } \\
\text { Stage }\end{array}$ & Kuningan City & Periodik \\
\hline
\end{tabular}

Sumber: Hasil Penelitian Data Sekunder, 2018
Sedangkan beberapa event dan pameran yang telah diselenggarakan diluar negeri yang diikuti oleh artis Indonesia dapat disampaikan pada olahan data sekunder sebagai berikut:

Tidak sedikit karya artis Indonesia dengan berbagi tipe dan kekhasan Indonesia diminati oleh pembeli dan konsumen yang didominasi dari pasar luar negeri. Beberapa artis menilai bahwa apresiasi karya lebih banyak berdatangan dari pembeli luar negeri ketimbang dari dalam negeri. Bahkan artis Indonesia pernah ada yang berkesempatan mendapatkan apresiasi dari perusahaan international untuk karya yang dibuatnya.

Artis Indonesia yang lebih dikenal dengan sebutan Kong Andri menjadi salah satu artis urban toys, yang terpilih bersama 29 designer

Tabel 2. Event Urban toys Luar Negeri

\begin{tabular}{|c|c|c|c|}
\hline No & Nama Event & Negara & $\begin{array}{l}\text { A r } \quad \text { t i } \\
\text { Indonesia }\end{array}$ \\
\hline 1 & $\begin{array}{l}\text { S ing a p ore } \\
\text { Toys and } \\
G \text { a m e s } \\
\text { Convention }\end{array}$ & & $\begin{array}{l}\text { B o w o } \\
\text { Bagaskara } \\
\text { Fadlin Nur } \\
\text { Ichwan }\end{array}$ \\
\hline 2 & $\begin{array}{l}\text { Th a i l a n d } \\
\text { Toys Fair }\end{array}$ & & $\begin{array}{l}\text { Komunitas } \\
\text { Sotoy }\end{array}$ \\
\hline 3 & $\begin{array}{l}\text { Toy Art } \\
\text { Galeri }\end{array}$ & Amerika & Paulus Hyu \\
\hline 4 & $\begin{array}{l}\text { Taipe } \\
\text { Festifal }\end{array}$ & Taipe & Paulus Hyu \\
\hline 5 & $\begin{array}{l}\text { Art Toys } \\
\text { F e s t i v a } 1 \\
\text { Award Jury }\end{array}$ & Amerika & $\begin{array}{l}\text { A b e } \\
\text { Oktovan }\end{array}$ \\
\hline 6 & $\begin{array}{l}\text { Project Toys } \\
\text { Android }\end{array}$ & Hongkong & Kong Andri \\
\hline
\end{tabular}

Sumber: Hasil Penelitian Data Sekunder, 2018 
toys lainnya berpartisipasi dalam project toys Android. Event tersebut diselenggarakan perusahaan Dead Zebra Inc. yang berkolaborasi dengan Google (Mazidah, 2015).

Artis urban toys Indonesia juga telah memasarkan produk karyanya hingga mancanegara. Seperti salah satu kutipan dibawah ini yang memberitakan mengenai peluang promosi artis Urban toys Indonesia dalam menembus pasar luar negeri. Salah satu artis urban toys senior Indonesia, Bowo Bagaskara, telah memasarkan Art Toys miliknya melalui media social, website, dan aktif mengikuti pameran. Karyanya banyak dijual ke Jakarta, Singapore, US, Australia, Thailand dan Hongkong (Mazidah, 2015).

Ditengah perkembangan yang positif terkait dengan dunia kreatif Urban toys di Indonesia, ternyata ada gejala anomali yang terlihat, dimana pembeli lokal (masyarakat dalam negeri) tidak menjadi pembeli potensial. Bukan berarti mereka tidak menyukai urban toys, namun pembeli lokal lebih menyukai buatan pabrik atau karya artis luar negeri. Seperti yang disampaikan oleh artis Indonesia yang dikutip dalam pemberitaan seputar dunia urban toys, Eric salah satu artis yang berkomentar, merasa perkembangan penggemar vinyl toys di Indonesia sebenarnya semakin banyak, namun pembeli dari masyarakat dalam negeri masih sangat kurang (MLDSPOT, 2017).
Beberapa artis akhirnya lebih banyak memasarkan karya urban toys-nya di luar negeri. Fenomena ini juga didukung oleh pernyataan salah satu artis Indonesia yang mengatakan bahwa:

"Pasar Indonesia masih banyak membeli Urban toys dari luar negeri dan belum mengapresiasi karya lokal, terkadang akhirnya mereka baru mau mengakui setelah karya lokal dilempar keluar negeri, dan pada saat itupula pembeli dalam negeri, mau membeli karya tersebut" (Oktaviani, 2018).

Beberapa permasalahan yang ditemukan dari pra penelitian ini yang terkait dengan komunikasi mendapati bahwa pihak peminat dalam hal ini masyarakat dalam negeri merasa bahwa karya artis luar negeri lebih bagus dan populer. Kecenderungan atas konsumsi produk populer inilah yang menjadi unsur persaingan bagi karya artis lokal. Adanya karya urban toys dengan konsep tradisional yang diusung oleh artis Indonesia tetap terasa kurang mendapatkan apresiasi dari dalam negeri. Sehingga pembeli lebih banyak berasal dari luar negeri, dan apresiasi media luar negeri pun lebih gencar dalam meng-expose karya urban toys artis Indonesia.

Adanya indikasi masalah dan latar belakang ini menghasilkan pertanyaan penelitian tentang bagaimana sebenarnya proses komunikasi visual yang dibangun artis Indonesia dalam membuat karya urban toys, khususnya dalam 
mengkombinasikan unsur tradisional kedalam produk populer.

Adapun tujuan dari penelitian ini adalah: (1) Untuk mengetahui fungsi urban toys dalam komunikasi visual. (2) Untuk mengidentifikasi model komunikasi visual dari produksi karya urban toys. (3) Untuk mengetahui aspek komunikasi visual yang dominan. (4) Untuk mengindentifikasi literasi komunikasi visual artis urban toys Indonesia.

Penelitian ini menggunakan theory of visual literacy yang digagas oleh Avgerinou dan Petersson di tahun 2011 yang menawarkan beberapa konsep diantaranya (1) Persepsi Visual. (2) Bahasa Visual. (3) Pembelajaran Visual. (4) Pemikiran Visual. (5) Komunikasi Visual (Petterson, 2015).

Teori ini digunakan karena salah satu konsep yang dibahas berkaitan dengan topik penelitian yaitu komunikasi visual. Mereka menyatakan juga bahwa teori visual literacy, merupakan serangkaian teknik dalam memproduksi pesan visual, baik dalam seni, pembelajaran dan kegiatan sehari (Petterson, 2015).

Petterson mengatakan bahwa literasi visual adalah sebuah keterampilan komunikasi, seperti layaknya komunikasi verbal, Lacy dalam (Petterson, 2015) mendefinisikan literasi visual sebagai berikut: "It (Visual literacy), can be defined as the ability to identify, interpret, evaluate and produce visual massage".Selain itu visual literasi, juga dibahas sebagai kemampuan memahami cara komunikasi visual dari bebagai media dan kemampuan mengespresikan paling tidak satu disiplin visual (Avgerinou, 1997).

Dalam pengembangan teori ini, juga dipaparkan mengenai kompetensi visual literasi. Fransecky dan Debes dalam (Petterson, 2015), mendefinisikannya sebagai kegiatan membaca, merencanakan dan membuat visualisasi serta mengkombinasikan visual dan verbal communication untuk komunikasi yang sengaja dibuat.

Adanya aspek kompetensi ini, memunculkan taksonomi outcomes dari literasi visual diantaranya sebagai berikut seperti dikatakan (Petterson, 2015): (1) Level Primer (PrimaryLevel), dimana pada level ini outputnya terdiri dari manipulasi seperti sentuhan dan perubahan terhadap objek. Konstruksi, seperti membuat karya yang sederhana, menggambar, mengambil gambar. Abstraksi, seperti identifikasi konsep, warna, bentuk dan nama objek. (2) Level Terampil (Skilled Level), pada level ini manipulasi dilakukan menggunakan alat untuk menyelesaikan masalah. Konstruksi, menggambar dengan perspektif, proses menggambar dengan lebih komplex. Abstraksi, membuat visual plan dua dimensi atau membuat visual dengan verbal. (3) Level Kemahiran (Advanced Level), pada tahap manipulasi, sudah pada mental manipulasi 
yang kompleks, konstruksi, kemampuan menggambarkan visualisasi tiga dimensi, produksi original conceptualization, produksi mix communication. Pada tahap abstraksi mampu mendeskripsikan konseptual ide secara verbal, yang unik dalam temuan visual.

Komunikasi Visual adalah salah satu konsep yang dipilih sebagai proses perancangan komunikasi visual. Hal ini menekankan bagaimana meletakan Urban toys sebagai bagian dari proses produksi pesan. Untuk itu dipilih konsep pendukung penelitian ini yakni komunikasi visual, sebagai proses berjalannya produksi Urban toys oleh perancang dalam hal ini adalah artis.

Komunikasi visual merupakan proses transmisi informasi, pesan atau ide kepada pihak lain menggunakan penggambaran, simbol dan lain sebagainya. Ini akan menjadi penguat komunikasi lisan dan teks, dan memiliki kekuatan tersendiri dalam persepsi orang. Bentuk komunikasi visual bisa dalam bentuk film, tipografi dan lain-lain. (White, 2018) Beberapa media visual yang memiliki tema dan pola yang dalam perkembangannya akan meningkatkan penerimaan persepsi dan emosional penerima pesan dari komunikasi visual, seperti pada dampak yang individual rasakan pada media spesifik seperti lukisan, gambar, patung dalam fine arts. (Barry, 2004) Pernyataan tersebut sebagai penguatan bahwa
Urban toys merupakan bagian dari media komunikasi visual.

Sedangkan proses komunikasi visual, penelitian ini mengambil referensi model dari Rune Pettersson yang membuat model komunikasi visual dalam pembuatan sebuah desain dalam media. Model tersebut diambil karena Petersson, mengacu pada beberapa model komunikasi yang ada seperti dari Shannon and Weaver, kemudian Wilbur Schramm dimana akhirnya Petterson pun membuat model komunikasi sendiri tahun 1983 dengan memasukan konteks budaya, serta persepsi dari komunikan. Hingga akhirnya secara spesifik Petterson menawarkan model komunikasi dalam perancangan komunikasi visual dalam design. Ada dua model yang ditawarkan satu adalah model komunikasi perancangan pesan dan model komunikasi perancangan media desain.

Penelitian ini melihat model komunikasi

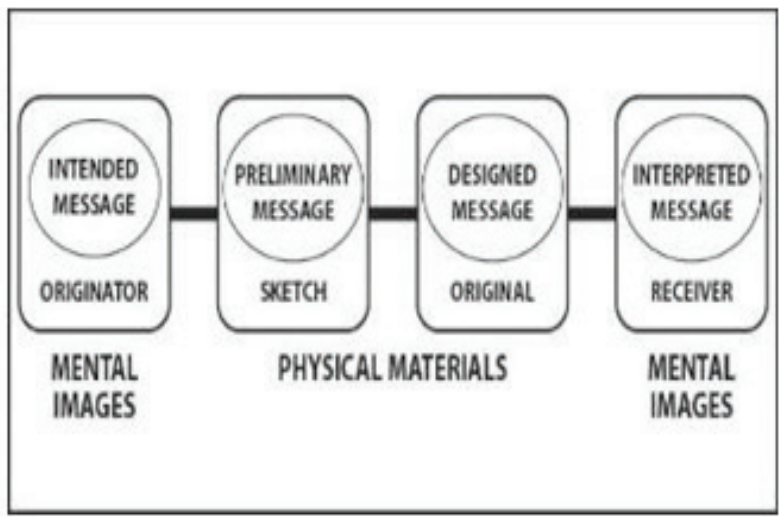

Sumber: Petterson, 2015

Gambar 2. Model Komunikasi Visual Perancangan Pesan 


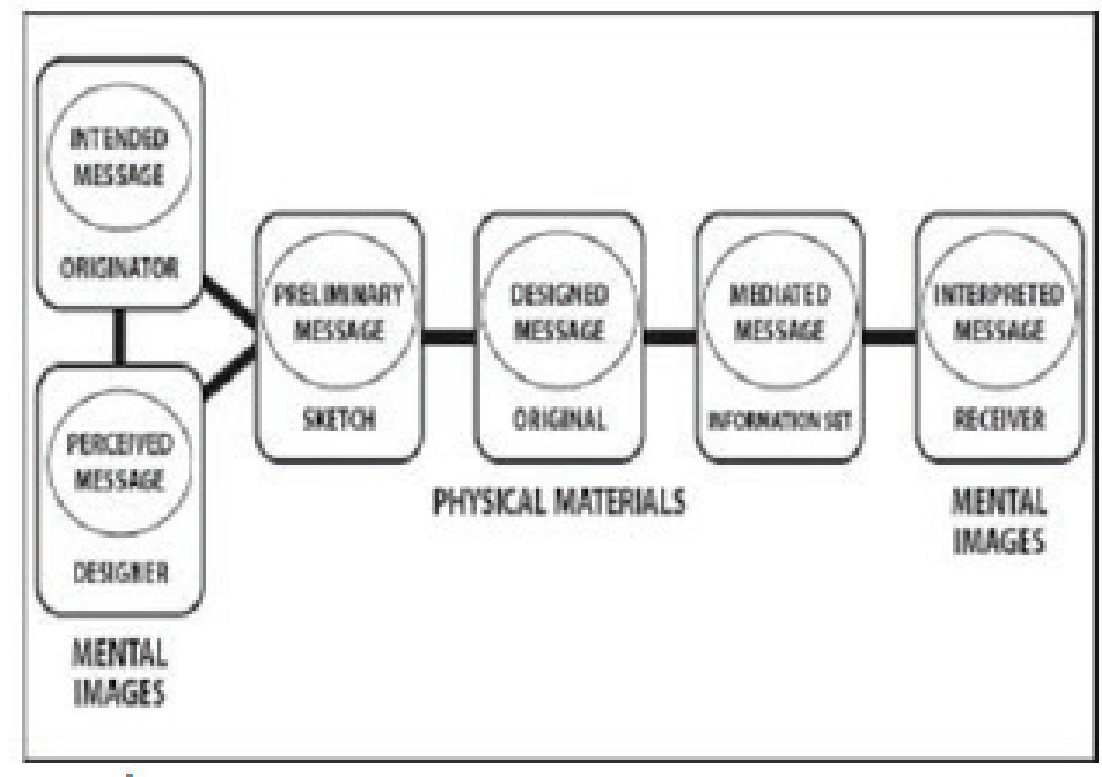

Sumber: Petterson, 2015

\section{Gambar 3. Model Komunikasi Visual Media Desain}

urban toys sebagai media, maka model komunikasi visual media desain juga menjadi rujukan untuk melihat bagaimana komunikasi urban toys di Indonesia (Petterson, 2015).

Penelitian ini terfokus pada urban toys, dimana dari proses komunikasi visual yang sengaja dirancang melahirkan produk "toys" yang menjadikan konsep bukan lagi mainan dalam konteks lama yakni "mainan saja", melainkan ada nilai yang ditaruh untuk menambah nilai dari urban toys yang diciptakan. Melihat adanya kondisi ini, konsep budaya popular juga masuk kedalam analisis nantinya, dimana beberapa asumsi produk urban ini memang melekat tidak jauh dari produk pop culture.

Menurut Ben Agger dalam (Hamid, 2012), sebuah budaya yang akan masuk dunia hiburan maka budaya itu umumnya menempatkan unsur popular sebagai unsur utamanya. Gagasan budaya populer oleh Ben Agger dapat dikelompokkan menjadi empat aliran, yaitu: (1) Budaya dibangun berdasarkan kesenangan tapi tidak substansial. Diartikan sebagai bentuk budaya yang mudah diterima oleh khalayak luas. (2) Kebudayaan populer menghancurkan nilai budaya tradisional. Budaya yang muncul sebagai budaya baru dan dapat mengikis budaya tradisional. (3) Kebudayaan menjadi masalah besar dalam pandangan ekonomi Max Kapitalis. Budaya populer berimbas pada orientasi profit, yang menjadi target dari pembuat budaya populer tersebut. (4) Kebudayaan populer merupakan budaya yang menetes dari atas. Beberapa diantaranya ada yang menyebutkan bahwa budaya tersebut berasal dari budaya 
yang disetting sedemikian hingga dari para pemilik modal.

Beberapa asumsi yang menjadi ciri khas budaya populer menurut Vidyarini adalah: (1) Tren, sebuah budaya yang berpotensi menjadi trend dan diikuti atau disukai banyak orang. (2) Keseragaman bentuk, karya manusia yang menjadi tren akhirnya diikuti oleh banyak pengikut. (3) Adaptabilitas, budaya populer mudah dinikmati dan diadopsi oleh khalayak, sejalan dengan tren yang berkembang. (4) Durabilitas, budaya populer juga dilihat berdasarkan durabilitas waktu, pelopor budaya populer yang dapat mempertahankan diri jika pesainnya tidak mampu menandingi keunikannya. (5) Profitabilitas, budaya populer berpotensi menghasilkan keuntungan yang besar bagi industri dan pihak yang mendukungnya (Vidyarini, 2008).

Dengan membawa teori dan konsep yang menjadi acuan literatur, penelitian ini khas pada aspek keterbaruan atau state of the art, yakni urban toys. Pemilihan ini didasarkan berkembangnya fenomena urban toys dari gerakan toys movement, yang masih jarang dijadikan kajian peneliti lainnya. Di Indonesia sendiri, masih sedikit penelitian yang membawa urban toys baik lokal ataupun perkembangannya di Asia kedalam kajian riset. Penelitian ini juga melihat proses pembuatan karya urban toys dilihat dari perspektif komunikasi, dimana produksi urban toys pada dasarnya sama seperti proses jalannya sebuah komunikasi. Baik dilihat dari aspek mikro ataupun makro yang mempunyai kepentingan produksi komunikasi.

Dengan membawa teori literasi visual sebagai bagian dari konfirmasi fenomena penelitian, dan juga merupakan bagian dari kekhasan penelitian ini, penelitian ini fokus terhadap proses bagaimana artis urban toys Indonesia merancang dan merencanakan konsep karya, dengan meninjau sejauh mana kekuatan dan kelemahan komunikasi visual artis Indonesia dalam menghasilkan karya urban toys. Bukan hanya dari aspek gagasan pribadi yang ditawarkan oleh artis, melainkan juga mengamati proses komunikasi yang berjalan dengan mengidentifikasi model komunikasi visual urban toys Indonesia. Hal ini dapat menjadi sumbangan baru pada dunia komunikasi, khususnya pada bidang komunikasi visual.

Dari model komunikasi visual yang dibahas, akan digambarkan pula bagaimana kombinasi budaya popular dengan tradisonal dapat menjadi terobosan tersendiri, dimana karya urban toys di Indonesia mulai memasukan unsur tradisional kedalam karya budaya populer. Hal ini diharapkan dapat memberikan sumbangan praktis bagi studi budaya popular.

\section{METODE PENELITIAN}


Penelitian ini menggunakan metode kualitatif deskriptif agar dapat memaparkan temuan penelitian yang spesifik, terkait dengan fokus penelitian, dengan paradigma konstruktivis yang berusaha menggali dan merekontruksi fenomena dan realitas yang terjadi, khususnya dalam fenomena urban toys yang berkembang di Indonesia. Pemaparan penelitian ini merupakan salah satu bagian dari Grant Research yang dilakukan untuk mengexplorasi urban toys di Indonesia. Riset ini melihat dan mendeskripsikan dari sudut pandang komunikasi visual. Dimana kajian ini berupaya menghasilkan temuan spesifik berkaitan dengan model komunikasi dalam proses pembuatan karya urban toys, dan fungsi urban toys dalam mempopulerkan budaya tradisional melalui media budaya popular.

Tahapan penelitian ini dapat dijelaskan dengan beberapa tahap yakni: Pra Penelitian (Februari 2018) dengan terlebih dahulu menetapkan tema dan mengidentifikasi fenomena, klasifikasi permasalahan penelitian, mengumpulkan literatur, penentuan narasumber. Penelitian (Maret-Juni 2018) dilakukannya wawancara, crosscheck (triangulasi), konfirmasi data sekunder, coding hasil wawancara dan melakukan analisis data. Laporan Penelitian (Juli-Agustus 2018) melaksanakan pembuatan laporan, penetapan simpulan, implikasi praktis dan akademis serta rekomendasi.
Penelitian ini menggunakan interview sebagai teknik pengumpulan data primer, dengan didukung oleh data sekunder sebagai penunjang interpretasi. Sumber penelitian ini adalah artis urban toys Indonesia yang ada di Jakarta. Adapun narasumber yang dipilih menjadi informan sebagai berikut: (1) Beberapa artis (Toys Designer) senior Indonesia, dipilih yang telah 5 tahun berkecimpung dalam membuat urban toys, (2) Artis (Toys Designer) Indonesia yang telah menembus pasar internasional, telah mengikuti event dalam dan luar negeri. (3) Anggota komunitas urban toys Indonesia, dipilih sebagai perwakilan untuk menyampaikan gagasan komunitas. (4) Akademisi (pakar budaya populer) guna menambah khasanah sekaligus cross check dalam sudut pandang budaya popular.

Penelitian ini menggunakan pengujian kehandalan data penelitian sebagai berikut: (1) Memilih narasumber yang relevan dan memiliki kompetensi yang sesuai dengan topik. (2) Melakukan crosscheck data melalui sumber sekunder. (3) Melakukan Intersubjectivity Agrement, dimana interpretasi dibandingkan dengan pandangan baik dari kajian literatur dan pandangan secara teoretis.

Analisis data dilakukan dengan menggunakan konsep Miles \& Huberman (Denzin, 2009): (1) Tahap orientasi atau tahap deskriptif: mendeskripsikan apa yang dilihat, 
didengar, dirasakan, ditanyakan. (2) Tahap reduksi /\&fokus: mereduksi segala informasi yang diperoleh pada tahap pertama. (3) Tahap seleksi: menguraikan fokus yang telah ditetapkan menjadi rinci atau paparan.

Selain proses analisis data, kekuatan interpretasi hasil analisis melalui teori menjadi salah satu sumber utama penelitian ini. Dalam literatur metodologi penelitian dan filsafat ilmu, dapat diidentifikasi minimal empat kegunaan teori dalam penelitian ilmiah, yaitu: (1) Menyediakan pola-pola bagi interpretasi data; (2) Mengaitkan satu studi dengan lainnya; (3) Memberikan kerangka dalam mana konsep-konsep dan peubah-peubah memperoleh keberartian khusus; (4) Teori juga memungkinkan peneliti menafsirkan makna yang lebih luas atau lebih dalam dari temuan temuan peneliti bersangkutan maupun bagi peneliti lain (Kumbara, 2018).

Penelitian ini bertempat di Jakarta, difokuskan pada workshop narasumber dan komunitas artis urban toys Indonesia.

\section{HASIL DAN PEMBAHASAN}

Berdasarkan hasil penelitian, urban toys berfungsi sebagai media komunikasi visual. Media disini dapat berupa platform untuk menyampaikan gagasan dan ide dari seorang artis urban toys. Ditinjau dari teori literasi visual, proses perancangan karya urban toys di Indonesia dapat dikategorikan sebagai bentuk "media sekaligus pesan" dalam konteks komunikasi visual. Hal ini dapat dijelaskan dalam konteks artis urban toys memproduksi karya sebagai media penyampaikan pesan, dan kreasi bentuk, menjadi visual pesan baik tersirat maupun tersurat.

Beberapa artis urban toys Indonesia menyampaikan bahwa sebelum membuat karya, mereka menetapkan tema dan bentuk karya berdasarkan kedekatan pesan dengan lingkungan. Sehingga fungsi utama urban toys adalah menyampaikan pesan yang diciptakan sebagai interpretasi hobi, pengalaman, kritik sosial, aspirasi politik, hingga pesan budaya lokal, hingga imajinasi artis itu sendiri. Kedekatan pada konteks lokal, menjadi latar belakang pembuatan karya urban toys, yang sekaligus menjadi ciri khas. Hal ini menguatkan afirmasi bahwa urban toys adalah bagian dari karya urban arts yang memiliki fungsi yang kurang lebih sama dengan para pelaku artis urban arts lainnya, yakni berusaha untuk menyampaikan pesan budaya dan pesan politik. (Bogerts, 2017).

Tema budaya diangkat dan muncul karena adanya ideologi dan concern terhadap banyaknya budaya Indonesia yang mulai dilupakan. Seperti salah satu hasil wawancara dengan artis yang mengatakan:

"Iya kadang kita bikin dan takjup dengan superhero luar negeri, terkadang itu buatan, 
tapi kan sebenernya Indonesia juga punya tokoh superhero, yang harusnya bisa dikenal oleh masyarakat kita sendiri atau luar negeri (Silvia Tampi)".

Adanya adopsi budaya tradisional kedalam media budaya populer menjadi bagian lain dari fungsi penggiringan persepsi visual dan pemikiran visual jika dikaitkan dengan teori visual literasi. Sebagai fungsi, media urban toys dapat membantu menerjemahkan budaya tradisional menjadi lebih menarik dan memiliki nilai tambah. Salah satu nilai tambah yang ditemukan dalam penelitian ini adalah urban toys sebagai media visualisasi yang lebih sederhana dan mudah dipahami oleh khalayak.

Dalam kaitannya dengan kajian literasi visual, urban toys dapat berfungsi sebagai media berupa pesan budaya yang disusun oleh para artisnya agar khalayak mampu membaca pesan dengan mudah dan atraktif. Seperti yang disampaikan Bamford dalam (Sidhartani, 2016) yang mengemukakan bahwa literasi visual mencakup kemampuan membaca dan menyusun sebuah pesan visual.

Selain unik dalam tema, urban toys, dalam penetapannya sebagai media komunikasi, dilihat dari aspek ukuran karya urban toys itu sendiri, yang dirancang diawal proses pembuatannya. Aspek ukuran ini menjadi bagian dari konsep artis yang berusaha menggabungkan karya populer dengan tradisional. Untuk saat ini lebih banyak artis Indonesia yang lebih memilih ukuran standar dalam menciptakan platform urban toys. Di Indonesia sendiri lebih banyak yang menggunakan ukuran 7 inchi dengan melihat aspek handy dan desain yang menarik.

Konsep penentuan ukuran media urban toys ini menjadi bagian dari preleminari message (Petterson, 2015) atau bagian dari sketsa awal dalam pembuatan kerangka pesan budaya. Tahapan ini merupakan tahap membangun persepsi khalayak penerima dengan stimulus yang menarik. Hal ini memungkinkan bagi khalayak yang belum mengenal budaya Indonesia dan akan memperluas imajinasi dari karya urban toys yang dibuat.

Urban toys adalah media tiga dimensi yang mereprentasikan pesan dan ideologi dalam proses pembuatan karya tersebut, sehingga merupakan bagian dari ranah komunikasi visual dan menyentuh ranah pembelajaran visual secara kreatif. Hal ini senada dengan unsur komunikasi visual yang menyatakan bahwa komunikasi adalah proses transmisi informasi, pesan atau ide kepada pihak lain menggunakan gambar, simbol atau ikon tertentu.

Jika dianalogikan dalam proses komunikasi, Urbantoysmerupakan sebuahmediakomunikasi penyampaian pesan serta konsep budaya sebagai gagasan. Artis merupakan komunikator dan khalayak sebagai komunikan/receiver. Keunikan produksi komunikasi visual karya urban toys Indonesia adalah adanya gabungan 


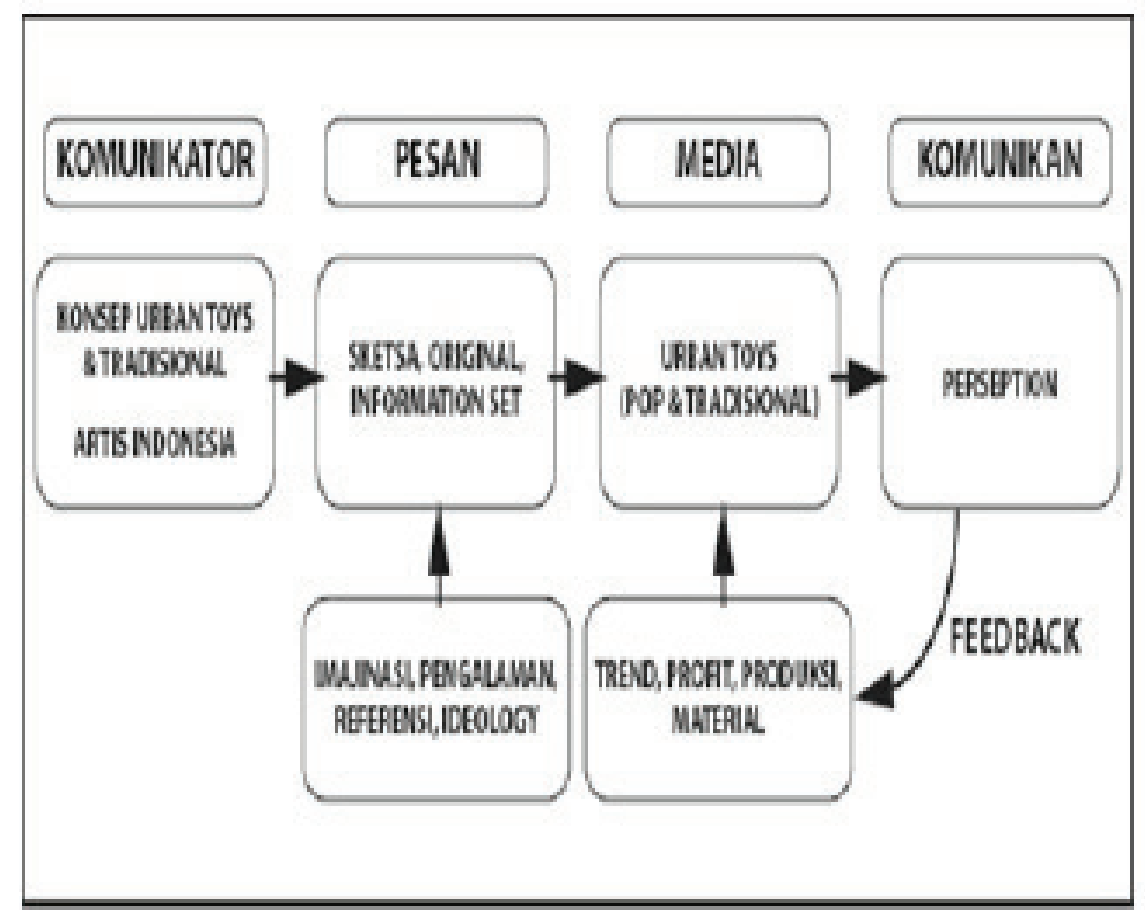

Sumber: Hasil Penelitian, 2018

\section{Gambar 4. Model Komunikasi Visual Original Konsep dari artis urban toys Indonesia}

unsur populer dan tradisional. Penelitian ini mengidentifikasi adanya dua jenis komunikator dari pembuat urban toys (artis) yakni originator dan designer. Originator sebagai komunikator adalah artis yang memproduksi platform awal, sedangkan designer adalah komunikator yang memanfaatkan platform artis lain untuk menghasilkan tema baru dalam karya urban toys.

Hasil penelitian menemukan ada beberapa artis Indonesia yang berperan dalam dua fungsi komunikator sekaligus, baik sebagai originator maupun sebagai designer. Contoh artis Indonesia yang menjadi komunikator dari aspek orginator dan designer dengan platform dan pesan budaya dimasukan secara bersamaan adalah Marine Ramdhani.
Contoh tersebut menunjukan bahwa desain populer dan tradisional sudah melebur, meskipun unsur populer masih lebih dominan dari unsur tradisional. Dari contoh diatas, proses komunikasi yang berlangsung dari aspek komunikator, media, dan pengelolaan pesan dapat dijadikan model komunikasi visual urban toys di Indonesia pada gambar 4.

Gambar 4 menggambarkan adanya alur komunikasi dari artis urban toys kepada khalayak untuk menggiring persepsi untuk kembali mengenal budaya Indonesia. Disini terlihat artis melakukan konstruksi pesan melalui media tiga dimensi, dalam hal ini adalah urban toys, dengan maksud menuangkan ideologi sekaligus imajinasi yang berasal dari konsep tradisional. Model ini juga menawarkan 
temuan tersendiri dimana urban toys, yang dapat dibuat secara mass product dan bernuansa pop culture, dapat menjadi alternatif dari media massa konvensional. Media massa konvensional dinyatakan dapat secara efektif menyebarkan pesaan ideologi, perlahan mulai berkurang dalam menginformasikan budaya tradisional Indonesia (Halwati, 2014). Terobosan urban toys dengan mengusung tema budaya, menjadi nuansa baru dalam menggiring kembali persepsi publik pada budaya tradisional.

Artis Indonesia yang menjadi komunikator dalam satu peran sebagai Designer saja cukup banyak. Artis seperti Sylvia Tampi, Bowo Bagaskara, Fadlin Nur Ichwan, Yonatan halim, dan Mirfu merupakan artis yang tergabung dalam komunitas urban toys di Indonesia.

Karya urban toys juga dapat merupakan gabungan fungsi komunikator, yakni berupa konsep yang dibuat oleh artis luar negeri dengan sentuhan konsep visual tradisional dari artis Indonesia. Artis lokal berperan meletakan tema budaya lokal ke dalam figure pop culture yang sudah terkenal, hal ini dilakukan agar khalayak tertarik dengan aspek populer sebagai mainan maupun dengan nilai tradisional Indonesia yang diselipkan di mainan tersebut.

Gabungan kedua artis, baik kolaborasi artis dalam dengan luar negeri atau, artis dalam negeri dengan artis dalam negeri sendiri, menjadikan karya urban toys mempunyai nilai tambah.
Nilai tambah tersebut terdapat pada: Pertama, melalui karya urban toys yang sudah terkenal dengan konsep tradisional yang melekat pada karya tersebut. Sebelumnya khalayak hanya membeli berdasarkan kepopuleran mainan tersebut, dengan adanya custom dari artis Indonesia, kini khalayak dapat menerima pesan budaya tradisional. Jika di gambarkan alur proses komunikasinya dapat dilihat pada gambar 5.

Berbeda dengan model sebelumnya, alur komunikasi ini cukup khas dan cukup banyak diimplementasikan oleh artis Indonesia. Selain tidak memerlukan waktu yang lama dalam mendesain pesan melalui platform awal, kekuatan urban toys yang sudah populer akan mendongkrak pesan tradisional dengan lebih cepat dan masif. Beberapa platform urban toys yang sudah terkenal ketika dimodifikasi oleh artis lokal cenderung lebih diminati.

Beberapa artis menilai bahwa melalui media urban toys yang sudah populer, resapan informasi kekhalayak akan lebih mudah diterima. Gabungan unsur kreatif artis luar negeri dan dalam negeri menjadi kolaborasi yang diminati khalayak, sehingga konsep tradisional yang diselipkan dalam urban toys akan memiliki nilai baru. Temuan ini menekankan adanya cara berpikir kreatif dari artis urban toys Indonesia dalam memadukan komunikasi visual tradisional kedalam media popular urban 


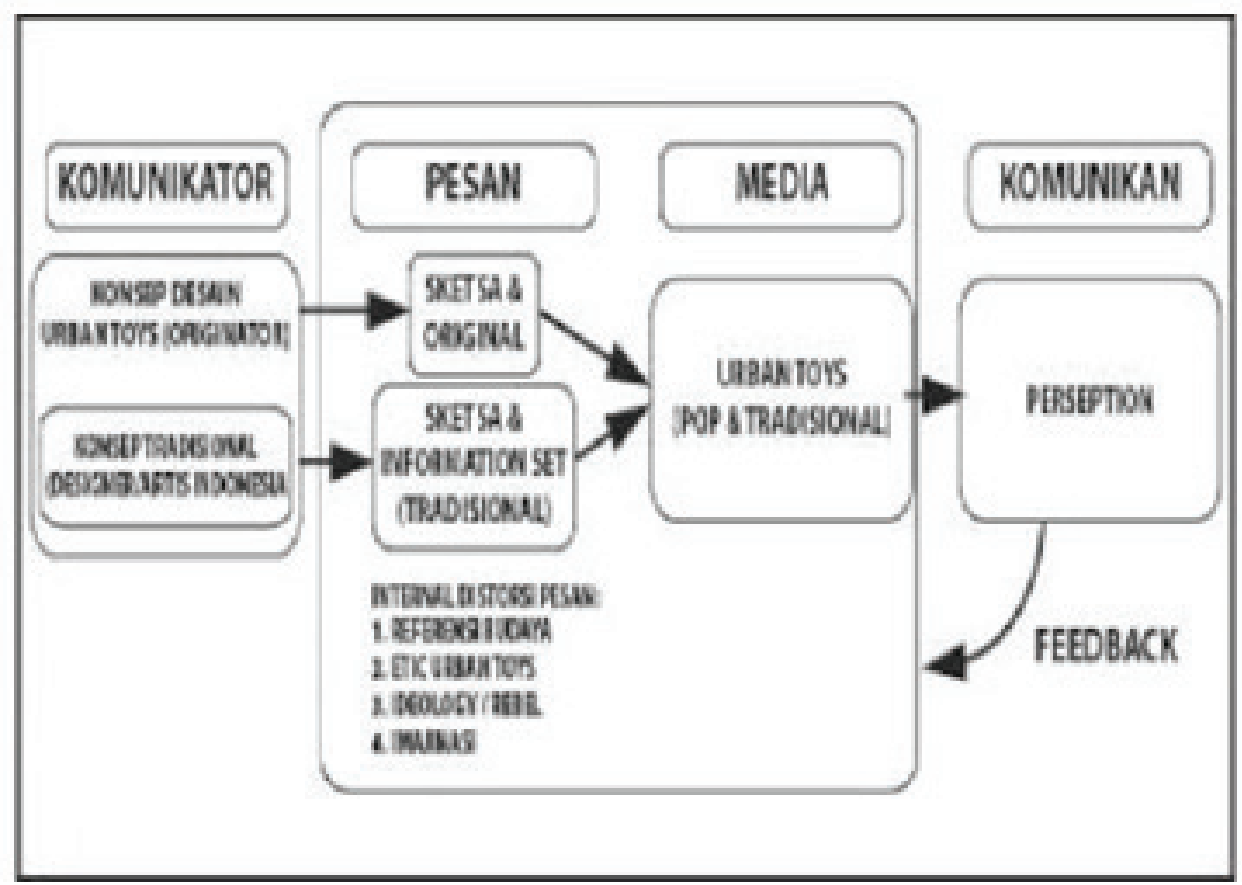

Sumber: Hasil Penelitian, 2018

Gambar 5. Model Komunikasi Visual Custom Konsep Dari Artis Urban Toys Indonesia

toys. Cara berfikir kreatif dinilai akan membantu dalam menggiring persepsi khalayak terutama dengan media yang memiliki unsur keunikan, media tersebut akan memberikan terpaan pesan, perhatian, pemahaman dan ingatan (Mirandha, 2017).

Konsep komunikasi visual kreatif ini yang menjadikan urban toys berkembang, bukan hanya sekedar mainan, melainkan menjadi media kreatif penyampaian gagasan budaya lokal. Seperti pada penelitian Setiawan (2017) yang menemukan bahwa konsep kreatif visual itu dapat mempermudah penyampaian ideologi dan pesan yang ingin disampaikan.

Penelitian ini juga melihat bahwa dalam merancang pesan, artis Indonesia lebih dominan dan mengedepankan Mediated Message untuk karya perpaduan populer dengan tradisional. Yang dimaksud disini adalah bagaimana dalam penyampaian pesan dengan aspek visual, belum begitu jelas aspek muatan pesan yang seperti apa yang berusaha disisipkan dalam karya urban toys.

Pada konteks produksi pesan, adanya noise/ gangguan justru muncul dari internal artis Indonesia sendiri. Seperti adanya perbedaan interpretasi atas referensi budaya, ideologi, nilai seni, hingga sikap rebel, dan profit oriented. Hal-hal tersebut menjadikan karya urban toys yang mengkombinasikan budaya tradisional dan populer menjadi amat bervariasi. Beberapa gangguan komunikasi visual bisa muncul dari salah satu unsur seperti bentuk, warna, skala, hingga detail yang tidak menyerupai tema 
budaya asli yang berusaha diterjemahkan. Berikut pernyataan dari salah artis urban toys yang menjadi narasumber:

"Iya, klo kita bikin urban toys dengan tema budaya Indonesia, cari referensinya paling dari internet, klo yang niat dari buku atau ensiklopedi”.

Temuan lain berkaitan dengan proses menciptakan komunikasi visual melalui urban toys, juga dirasakan oleh artis Indonesia, dimana salah satu narasumber mengatakan ideologi dalam karya urban toys berbanding terbalik dengan profit. Jika kita murni membuat karya dengan nilai seni, budaya murni atau ideologi artis maka implikasinya adalah pada penjualan karya urban toys. Hal ini disampaikan oleh salah satu artis urban toys Indonesia:

"Semakin original dan kuat ideologi yang dimasukan kedalam karya urban toys, maka akan sedikit peluang profit yang akan ditrima".

Jika melihat pendapat yang menyatakan bahwa budaya populer merupakan bagian dari kebudayaan dan menjadi masalah besar dalam pandangan ekonomi Max Kapitalis. Urban toys, karya Indonesia yang notabene adalah produk populer, masih dalam sebuah perspektif yang memandang karya yang memiliki daya tarik yang besar dimata khalayak adalah karya yang kental akan budaya popular serta memiliki nilai keuntungan yang besar. Sehingga sebagai media, urban toys saat ini dinilai baru memberikan nilai tambah dan belum menjadi kombinasi muatan tradisional yang murni sebagai penyalur ideologi dan pesan, dalam hal ini konsep dan gagasan artis.

Temuan menarik lainnya adalah keberadaan budaya tradisional yang terdapat pada urban toys akan memiliki nilai jual tinggi jika dikombinasikan secara seimbang atau lebih cenderung dominan budaya populernya. Sedangkan jika urban toys murni merujuk pada ideologi artis dan kental akan budaya tradisional saja, maka khalayaknya akan menjadi lebih tersegmentasi.

Artis Indonesia menjadikan urban toys sebagai media alternatif untuk menyampaikan budaya tradisional dengan menggunakan kemasan urban toys yang dibuatnya. Keunikan ini menjadi sumbangan industri kreatif dalam promosi budaya Indonesia. Kejelian artis memanfaatkan karya populer sebagai media pesan budaya menjadikan nilai komunikasi visualnya lebih kreatif. Temuan penelitian ini juga didukung oleh penelitian sebelumnya yang mengatakan bahwa budaya populer dapat mengkontruksi perilaku khalayak (Ridharyanti, 2014)

Adanya temuan penelitian pada komunikasi visual urban toys ini, memberikan sumbangan teoretis, dimana sebelumnya menurut kebudayan popular dapat menghancurkan budaya tradisional. Namun dengan kreasi penggabungan karya ini, memberikan kondisi 
yang berbeda dengan pernyataan Arger tersebut. Gagasan meletakan konsep budaya tradisional kedalam media populer menjadikan kedudukan urban toys sebagai media alternatif untuk mendongkrak budaya tradisional.

Cara bercerita yang khas dari designer toys dalam karya yang dibuat untuk menyampaikan pesan budaya tradisional dengan unsur keunikan dan kreasi imajenasi ini tampak dominan. Budaya tradisonal sifatnya masih menempel pada budaya popular, namun prinsip penggunaan budaya populer dapat menjadi terobosan dalam mempopulerkan budaya tradisional.

Perpaduan budaya dalam konsep urban toys di Indonesia ini, belum sampai pada proses menjadi homogen, atau istilah dalam kajian budaya populer dikenal sebagai proses menyebarkan budaya bangsa secara menyeluruh melalui budaya populer (Ikhsano, 2018).

Jika melihat dari aspek kompetensi, artis Indonesia, dalam upaya mengkomunikasikan budaya tradisional kedalam platform urban toys, dinilai telah mahir atau terampil dalam proses komunikasi visual. Beberapa bahkan mampu untuk meramu secara seimbang antara konsep tradisional dengan konsep baru urban toys melalui karyanya. Beberapa ada yang menyelipkan konsep tradisional kedalam platform urban toys yang sudah ada.

Dari dua bentuk proses pembuatan karya, mereka dapat dikategorikan sebagai artis pada advance level. Jika dikaitkan dengan kompetensi, mereka sudah menerapkan beberapa aspek kriteria pada mental manipulasi dengan bentuk yang kompleks, adanya proses konstruksi, kemampuan menggambarkan visualisasi tiga dimensi, produksi original konseptualiasi, produksi mix communication. Pada tahap abstraksi mampu mendeskripsikan konseptual ide secara verbal, unik temuan visual (Petterson, 2015).

Meskipun demikian Urban toys di Indonesia masih kental dan dominan pada unsur budaya populer ketimbang media baru yang tradisional. Adanya etika dalam pembuatan urban toys yang menggabungkan pop culture dengan budaya tradisional, menjadikan unsur tradisional tidak dapat menjadi dominan dan tidak boleh merubah platform awal, atau sebaliknya jika membuat secara orisinal tidak dapat mengikuti pakem mainan tradisional yang sudah ada.

Hal ini dikuatkan oleh penelitian sebelumnya yang menyatakan bahwa dalam penyampaikan pesan budaya melalui urban toys, masih memiliki kelemahan dalam proses penyampaian pesan. Adanya distorsi pesan ketika menaruh konten tradisonal pada platform Urban toys modern adalah salah satunya. Beberapa hal lain muncul disebabkan karena kurangnya referensi dalam pembuatan karya tradisional, termasuk tidak adanya standar pembuatan karya tradisional di 
Indonesia, menjadikan kebebasan artis dalam menerjemahkan imajinasi mereka menjadi beragam. Artis urban toys Indonesia dalam membuat karya, belum sampai pada tahap menghasilkan pesan budaya yang kompleks dan memiliki kontinuitas, sehingga belum dapat menjadi media tandingan ataupun promosi budaya Indonesia yang kuat (Oktaviani, 2018).

Beberapa artis belum menjadikan tema pesan budaya menjadi tema yang berkelanjutan, beberapa ada yang terjebak dalam pemikiran profit oriented sehingga beberapa artis lebih fokus pada konsep modern. Belum adanya kesinambungan dalam memproduksi karya urban bertema budaya Indonesia menjadikan ideologi artis Indonesia dalam mengkomunikasikan budaya tradisional masih samar antara orientasi profit atau murni idealisme. Temuan menarik lainnya adalah, kemampuan literasi komunikasi visual yang telah dimiliki dengan baik oleh artis urban toys Indonesia, walaupun pada akhirnya masih kalah dengan pemikiran atas profit dan kekhawatiran atas respon dan persepsi publik. Realita ini menggambarkan bahwa komunikasi visual dalam produksi pesan urban toys merupakan bagian dari proses desain yang kompleks dan sangat terkait dengan unsur sosial, budaya dan ekonomi (Gwilt, 2011).

\section{SIMPULAN}

Urban toys dalam komunikasi visual memiliki fungsi sebagai media untuk menyampaikan gagasan. Gagasan yang diusung oleh artis Indonesia berupa, visualisasi karya seni, kritik sosial, aspirasi politik, hingga pesan budaya. Dalam fungsinya sebagai media alternatif, urban toys, bersifat kreatif dan berbentuk tiga dimensi, dinilai kuat dalam memvisualisasikan bentuk pelestarian budaya tradisional Indonesia. Perpaduan antara karya popular dan konsep lokal menjadikan urban toys memiliki keunikan dalam penyampaian pesan budaya tradisional.

Terdapat dua model komunikasi visual dari proses pembuatan urban toys di Indonesia. Model komunikasi visual yang lebih banyak digunakan adalah model kedua, yakni adanya gabungan komunikator antara artis urban toys luar negeri sebagai orginator dan artis Indonesia sebagai designer custom yang menyisipkan pesan tradsional. Untuk model komunikasi visual yang pertama, masih relatif sedikit artis Indonesia yang menjalankan dua peran sekaligus, baik sebagai originator maupun designer.

Sedangkan dalam aspek komunikasi, pembuatan pesan, urban toys lebih dominan sebagai mediated message, yakni urban toys sebagai media perantara dalam penyampaian pesan tradisional Indonesia kepada khalayak. Muatan tradisional yang masuk dalam karya 
populer, merupakan cara bercerita yang khas designer toys Indonesia atas karya yang dibuat. Meskipun dari hasil pengamatan, konsep budaya populer masih lebih dominan daripada visualisasi tradisionalnya.

Komunikasi visual Urban toys, dapat masuk sebagai bagian dari proses menggiring persepsi publik. Urban toys dapat masuk sebagai alternatif gabungan media populer dan tradisional. Nilai tradisional terangkat, melalui persepsi khalayak yang mengetahui bahwa konsep tersebut dibuat dari karya populer yang disukai banyak kalangan.

Dari dua model proses komunikasi visual pembuatan karya, kompetensi artis di Indonesia dapat dikategorikan pada advance level. Dimana artis Indonesia sudah menerapkan beberapa aspek kriteria kompetensi seperti pada mental manipulasi dengan bentuk yang kompleks, adanya proses konstruksi pesan, kemampuan menggambarkan visualisasi tiga dimensi, produksi original konseptualiasi, hingga konsep produksi mix communication. Disini artis tidak hanya sekedar menciptakan karya dengan imajinasi visual individu, melainkan membangun gagasan pesan tradisional untuk dinikmati oleh khalayak.

Penelitian ini menyodorkan implikasi teoretis bahwa urban toys di Indonesia, dapat menggabungkan konsep tradisional kedalam karya populer. Kedudukan urban toys dapat menjadi proses komunikasi visual yang dapat dikembangkan menjadi media penyampaian pesan tradisional. Dalam teori dan konsep sebelumnya, menyatakan bahwa budaya populer dapat menghancurkan budaya tradisional, namun temuan penelitian ini memperlihatkan bahwa sebenarnya budaya popular dapat menjadi media dalam penyampaian pesan budaya tradisional.

Dari hasil penelitian, direkomendasikan kepada artis atau penggiat urban toys di Indonesia, untuk dapat mengimplemantasikan keahlian merancang pesan dengan tema tradisional dengan konsisten. Rancangan praktis juga disarankan kepada artis dan komunitas untuk dapat membuat buku kumpulan karya urban toys yang telah dibuat dari beberapa artis, sehingga dapat menyebarkan pesan visual tradisional melalui buku bertema pop art.

Saat ini karya urban toys Indonesia masih lebih dominan pada nuansa populer, sehingga disarankan kepada artis untuk dapat membentuk komunitas dan memproduksi karya dengan mengacu pada literasi budaya tradisional. Sehingga pesan yang dibangun dalam mengkomunikasikan tema tradisional dapat lebih seimbang porsinya dengan platform populer. Kemudian juga disarankan untuk dapat membuat caption dari setiap karya urban toys yang dibuat, agar dapat membantu menjelaskan pesan tradisional yang ada. 


\section{DAFTAR PUSTAKA}

Atilgan, N. S. (2014). Designer activity through open source knowledge: designer toys movement. Social and Behavioral Sciences, 122, 35-39. https://doi.org/10.1016/j. sbspro.2014.01.1299

Avgerinou, M. (1997). A review of the concept of visual literacy. Bristish Journal Of Educational Technology, 28(4), 282.

Barry, A. (2004). Perception theory. in s. m. ken smith, handbook of visual communication. London: Routledge.

Bogerts, L. (2017). Mind the trap: street art, visual literacy, and visual resistance. Sauc Journal, 3(2), 6-10.

Denzin, N. K. (2009). Handbook of qualitative research. Yogyakarta: Pustaka Pelajar.

Gwilt, I. (2011). Framing futures for communication visual design research. design priciples and pratices. International Journal, 82-98.

Halwati, U. (2014). Konstruksi publikasi nilainilai ideologi dalam pers ( media massa). Jurnal Komunikasi Penyiaran Islam, 168180.

Hamid, F. (2012). Media dan budaya poluler. Komunika, 15(1), 11-15.

Ikhsano, A. (2018). Budaya populer. Hasil Wawancara.

Kumbara, A. N. (2018). Genealogi teori dan metodologi di cultural studies. Jurnal Studi Kultural, 3(1), 35-46.

Mazidah, I. (2015). Peluang usaha kontan.
Diambil 12 September 2015, dari http:// peluangusaha.kontan.co.id/news/potensimainan-art-toys-tak-main-main

Mirandha, I. Y. (2017). Perbandingan persepsi khalayak antara iklan yang mengandung humor dan tidak mengandung humor. Jurnal Profesi Humas, 1(2), 112-123.

Oktaviani, R. C. (2018). Urban toys as a new alternative media to promote Indonesian culture. Malaysian Journal of Communication, 34(4), 303-318.

Petterson, K. (2015). Message design. Swedia: Institute For Infology.

Ridharyanti, M. (2014). Bentuk budaya populer dan konstruksi prilaku konsumen studi terhadap remaja. Jurnal Visi Komunikasi, 87-104.

Sidhartani, S. (2016). Literasi visual sebagai dasar pemaknaan dalam apresiasi dan proses kreasi visual. Jurnal Desain, 155163.

Vidyarini, T. N. (2008). Budaya populer dalam kemasan program televisi. Jurnal Ilmiah Scriptura, 29-37.

White, D. (2018). Study academy lesson. Diambil dari https://study.com/Academy/ Lesson/What-Is-Visual-CommunicationDefinition-History-Theory-Examples. Html\#Transcriptheader

Yusrini, F. (2017). Serunya para kolektor berburu urban toys. Diambil 31 Maret 2018, dari www.femina.co.id:https://www. femina.co.id/trending-topic/serunya-parakolektor-berburu-urban-toys-? $p=$ 